\title{
Recent accumulation variability in northwest Greenland from ground-penetrating radar and shallow cores along the Greenland Inland Traverse
}

\author{
Robert L. HAWLEY, ${ }^{1}$ Zoe R. COURVILLE, ${ }^{2}$ Laura M. KEHRL, ${ }^{1 *}$ Eric R. LUTZ, ${ }^{1}$ \\ Erich C. OSTERBERG, ${ }^{1}$ Thomas B. OVERLY, ${ }^{1}$ Gifford J. WONG ${ }^{1}$ \\ ${ }^{1}$ Department of Earth Sciences, Dartmouth College, Hanover, NH, USA \\ E-mail: robert.I.hawley@dartmouth.edu \\ ${ }^{2}$ US Army Corps of Engineers, Cold Regions Research and Engineering Laboratory, Hanover, NH, USA
}

\begin{abstract}
Accumulation is a key parameter governing the mass balance of the Greenland ice sheet. Several studies have documented the spatial variability of accumulation over wide spatial scales, primarily using point data, remote sensing or modeling. Direct measurements of spatially extensive, detailed profiles of accumulation in Greenland, however, are rare. We used $400 \mathrm{MHz}$ ground-penetrating radar along the $1009 \mathrm{~km}$ route of the Greenland Inland Traverse from Thule to Summit during April and May of 2011, to image continuous internal reflecting horizons. We dated these horizons using ice-core chemistry at each end of the traverse. Using density profiles measured along the traverse, we determined the depth to the horizons and the corresponding water-equivalent accumulation rates. The measured accumulation rates vary from $\sim 0.1 \mathrm{~m}$ w.e. $\mathrm{a}^{-1}$ in the interior to $\sim 0.7 \mathrm{~m}$ w.e. $\mathrm{a}^{-1}$ near the coast, and correspond broadly with existing published model results, though there are some excursions. Comparison of our recent accumulation rates with those collected along a similar route in the 1950s shows a $\sim 10 \%$ increase in accumulation rates over the past 52 years along most of the traverse route. This implies that the increased water vapor capacity of warmer air is increasing accumulation in the interior of Greenland.
\end{abstract}

KEYWORDS: accumulation, ground-penetrating radar, ice-sheet mass balance, polar firn

\section{INTRODUCTION}

The growth and decay of ice sheets is driven by a balance between accumulation of snow on the surface, primarily in the high-elevation interiors, and the melting, runoff, evaporation, sublimation and iceberg calving that takes place primarily along the lower-elevation margins. The mass balance of the Greenland ice sheet, in particular, is of increasing importance to scientists and policymakers, as rising air and ocean temperatures have increased the rate of melting and the velocity of calving outlet glaciers, contributing to a rising sea level (Lemke and others, 2007). The net mass balance of the Greenland ice sheet has been the subject of much recent work (e.g. Alley and others, 2007; Rignot and others, 2008; Wouters and others, 2008; Zwally and others, 2011). Additionally, investigators have studied the surface mass balance, primarily accumulation, using point measurements (Benson, 1962; Ohmura and Reeh, 1991; Dibb and Fahnestock, 2004; Bales and others, 2009), automated weather stations (e.g. GC-Net: http://cires. colorado.edu/science/groups/steffen/gcnet/), remote sensing (Drinkwater and others, 2001; Kanagaratnam and others, 2001; Hawley and others, 2006), and more recently, using climate models constrained by observations (Box and others, 2004, 2013; Bales and others, 2009; Burgess and others, 2010; Hanna and others, 2011). Spatially extensive groundbased profiles of accumulation rates, however, are rare (Benson, 1962). The spatial variability of accumulation on

*Present address: Department of Earth and Space Sciences, University of Washington, Seattle, WA, USA. varying length scales is difficult to determine with point measurements or climate models, especially when local topography is considered.

Here we derive spatially extensive measurements of accumulation along a $1009 \mathrm{~km}$ traverse from $\sim 1700 \mathrm{~m}$ a.s.l. in northwest Greenland to the $\sim 3200 \mathrm{~m}$ a.s.l. center of the ice sheet. We trace internal reflecting horizons (IRHs) in $400 \mathrm{MHz}$ ground-penetrating radar (GPR) data. We use density profiles collected along the traverse to calculate electromagnetic wave speed through the snow and firn in order to determine the depth of the IRHs, and date the IRHs using snow/firn chemistry data from cores collected at each end of the traverse.

\section{THE GREENLAND INLAND TRAVERSE}

During the spring of 2011, a science field team from Dartmouth College joined the Greenland Inland Traverse (GrlT), an effort funded by the US National Science Foundation to take heavy and bulky resupply items to Summit station, at the center of the Greenland ice sheet. The GrIT 2011 convoy consisted of three Case tractors, each hauling cargo, and a single Pisten Bully tractor hauling the science team and their equipment. Along the traverse route (Fig. 1), the science team collected continuous geodeticquality GPS profiles and GPR data. At selected points along the route, the team made point measurements: snow pits (five pits, $<2 \mathrm{~m}$ depth) for physical and chemical stratigraphic analyses, and shallow cores (six cores, $<10 \mathrm{~m}$ depth) for density profiling. The locations for these stops were a compromise between high sample frequency (every 


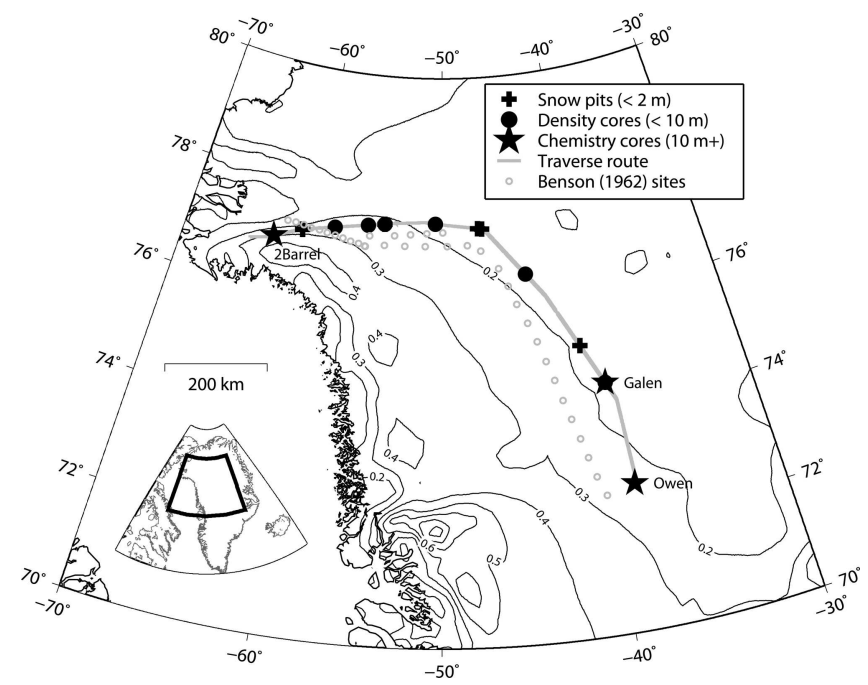

Fig. 1. Field locations along the Greenland Inland Traverse route. The route is marked in dark gray. Gray circles mark the Benson (1962) pit locations. Shallow pits and cores for density are shown as crosses and filled circles, respectively, and ice cores drilled for chemical analysis and dating are shown as stars. Contours (after Burgess and others, 2010) are accumulation (mw.e.), modeled using Polar MM5 for the year 1958, showing the general spatial pattern of accumulation in this region.

$\sim 40 \mathrm{~km}$ ) along the route and the expeditious transport of cargo to Summit. Thus the science team sampled as frequently as feasible without impeding progress. The traverse team spent 24 days traveling from Thule to Summit, hauling cargo and making science stops, and 11 days traversing back to Thule. While GPS and GPR profiles were collected in both directions, here we report only the profiles collected from Thule to Summit. We use point measurements of density from both legs.

\section{METHODS}

\section{Positioning using GPS}

We collected differential GPS data using a Trimble NetR8 reference receiver, with a Zephyr Geodetic antenna mounted to the roof of the Pisten Bully. In addition to our geodetic-grade GPS receiver, we also operated a navigationgrade Garmin GPS receiver, recording positions along the traverse route as a regular part of navigation.

We processed the GPS data using TRACK, the kinematic processing module of the GAMIT/GLOBK suite (King and Bock, 2009). Estimated root-mean-square horizontal values were generally between 13 and $18 \mathrm{~cm}$, largely due to long baselines. Occasionally there were gaps in the TRACK output, due to extensive phase ambiguities, multipath signals or unknown causes. If these gaps spanned $<5$ min, we inserted navigation-grade GPS data recorded from the Garmin GPS. If these gaps spanned $>5$ min, we discarded the corresponding GPR data.

\section{Ground-penetrating radar}

We collected GPR data using a Geophysical Survey Systems Inc. (GSSI) SIR-3000 radar unit with a $400 \mathrm{MHz}$ antenna. The choice of frequency was a trade-off between range resolution in discriminating IRHs and total range; lower frequencies can image deeper IRHs at the expense of lower depth resolution. The antenna was towed on the snow surface in a small plastic sled, affixed to a wooden 'outrigger' that held the sled out of the impressions left by the tracks and kept the antenna $\sim 3 \mathrm{~m}$ away from the metal of the vehicle. We recorded 2048 samples per trace over a range window of $600 \mathrm{~ns}$. At a relative permittivity of $\sim 2.4$, typical of dry-firn conditions, the range was $\sim 58 \mathrm{~m}$. The $400 \mathrm{MHz}$ short-pulse radar we used has a range resolution (ability to resolve distinct features) of $\sim 0.35 \mathrm{~m}$ in firn (Spikes and others, 2004). We recorded 16 traces per second, which at the Pisten Bully's average travel speed of $\sim 3.2 \mathrm{~m} \mathrm{~s}^{-1}$ results in 5 traces recorded per meter. Note that this spacing between traces varies with the vehicle speed.

We computed the position of each trace using our differential GPS measurements. To co-register GPR and GPS data, we used time stamps embedded in the two data streams. To reduce data volume and increase the signal-tonoise ratio, we 'stacked' the radar data by averaging adjacent traces together. Rather than choosing a number of traces to stack, we stacked using a fixed distance, based on our GPS measurements. We stacked each $20 \mathrm{~m}$ stretch of traces together, generally resulting in a stack of between 70 and 120 traces. The final radargram of the entire GrIT route is shown in Figure 2. We did not apply any timevariable gain or filtering.

\section{Snow/firn density profiles}

We measured density profiles along the traverse using snowpit and core samples. In each snow pit, we used a cutter of a known volume to excise a snow sample, and weighed the sample. Using the cutter we measured density at $0.1 \mathrm{~m}$ resolution throughout the depth of each snow pit $(\sim 1 \mathrm{~m})$. At many locations we were able to extend the density profile by drilling shallow cores for density only. We determined densities from these cores by measuring the diameter, length and mass of $10-20 \mathrm{~cm}$ core sections. Finally, we measured densities from cores extracted on the traverse for chemical analysis, as well as a published density profile from Summit (Hawley and others, 2008).

\section{Travel-time to depth conversion}

In order to estimate a density profile for each radar trace to determine electromagnetic wave velocity, and thus depth, we interpolate linearly along constant depths between density profiles. At any given depth, we interpolate between all of the profiles that exist at that depth. Thus our interpolation becomes spatially coarser as fewer points reached the greatest depth. Our scheme is limited by the depth of the shallower ('2Barrel') of the two end profiles, and beyond this depth we use the density from the deeper Summit core. The final density array we use is shown in Figure 3. We use these densities to convert from two-way travel time to depth.

The electromagnetic wave speed, $\nu\left(\mathrm{m} \mathrm{s}^{-1}\right)$, is related to the dielectric permittivity, $\epsilon_{\mathrm{r}}$ (dimensionless), and the speed of light in a vacuum, $c\left(\sim 3 \times 10^{8} \mathrm{~m} \mathrm{~s}^{-1}\right)$, by

$$
\nu=\frac{C}{\sqrt{\epsilon_{\mathrm{r}}}} .
$$

The relative permittivity of snow and firn is related to density, $\rho\left(\mathrm{g} \mathrm{cm}^{-3}\right)$, following Kovacs and others (1995):

$$
\epsilon_{\mathrm{r}}=(1.0+0.845 \times \rho)^{2} .
$$

We identified the direct-coupling wave in the radar profiles, and set the depth to zero at that point. We then calculated 


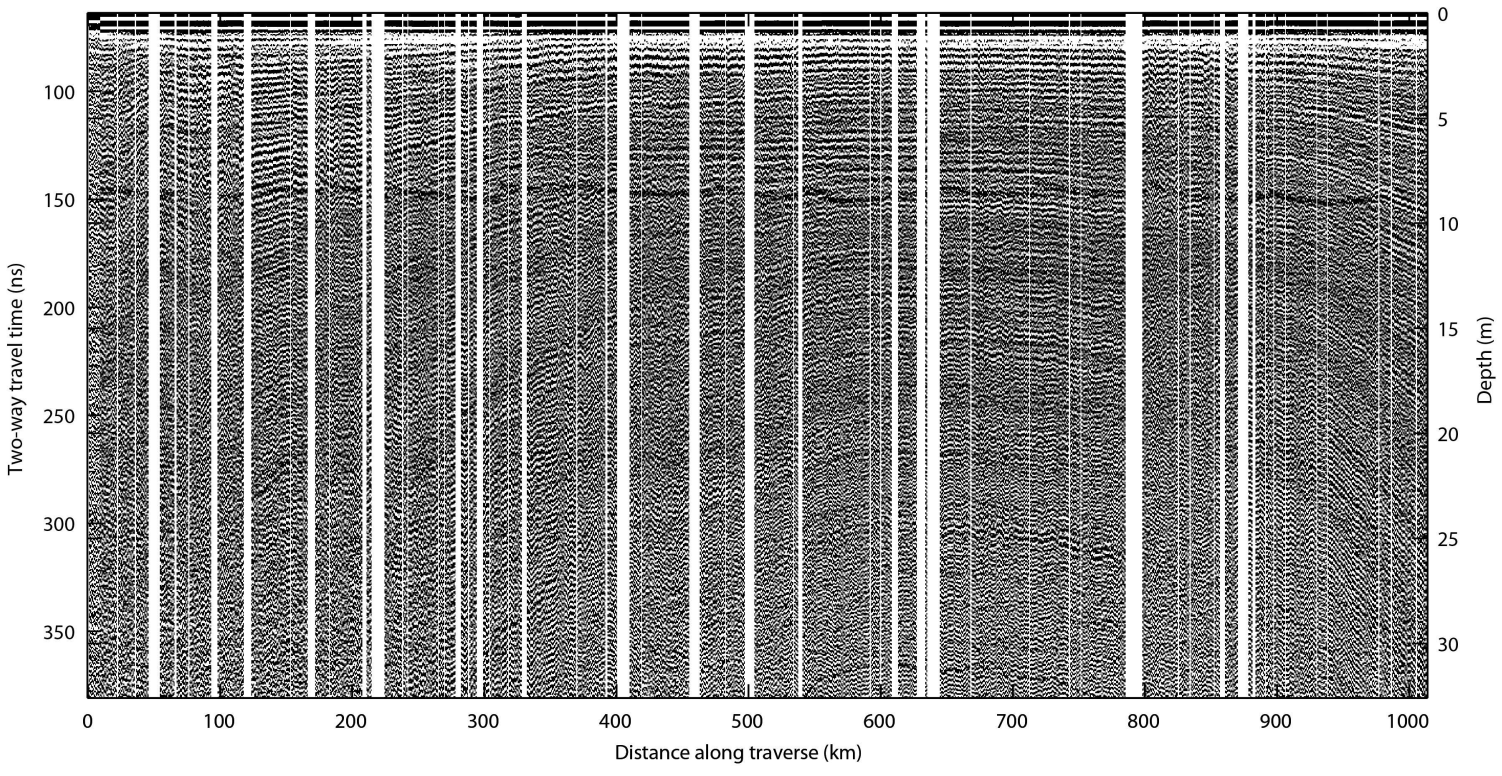

Fig. 2. Radargram of the GPR data collected along the GrIT route (Fig. 1). Thule airbase is to the left, Summit station is to the right. Though we have not applied any gains or filters, IRHs are clearly evident. Dated cores on either end of the traverse confirm these layers to be isochrones. Vertical striping results from gaps in either GPR or GPS data; if positioning was not well constrained for the GPR data, we discarded it.

the depth for each subsequent GPR sample, consecutively, using the velocity profile of the firn above that sample. In this way we avoided using an average velocity for depth determination.

\section{Core depth/age scales}

We collected three cores for glaciochemical analysis: one close to each end of the traverse route, and one along the route (Fig. 1). The 'Owen' core was drilled to $100 \mathrm{~m}$ depth at Summit in summer 2010. The '2Barrel' core was drilled to $20 \mathrm{~m}$ depth near Camp Century $\left(76.93535^{\circ} \mathrm{N}\right.$, $\left.63.15386^{\circ} \mathrm{W}\right)$ in summer 2011. The 'Galen' core was drilled to $10 \mathrm{~m}$ depth at $74.42233^{\circ} \mathrm{N}, 39.29433^{\circ} \mathrm{W}$ at $\sim 800 \mathrm{~km}$ along the traverse route, also in 2011. To account for the year between cores, we adjusted the Owen depth using a published mean accumulation rate from Summit (Dibb and Fahnestock, 2004). We processed and sampled all three cores in the Dartmouth ice-core chemistry laboratory, using a continuous melter system with discrete sampling (cf. Osterberg and others, 2006). The melter system collected samples continuously with a sampling interval of $4-10 \mathrm{~cm}$, producing 6-20 samples each year for all three records. We measured stable water isotope ratios ( $\delta \mathrm{D}$ and $\delta^{18} \mathrm{O}$ ) using a Picarro L2310-i isotope analyzer with a typical analytical uncertainty of $\pm 0.4 \%$ for $\delta \mathrm{D}$ and $\pm 0.2 \%$ for $\delta^{18} \mathrm{O}$. We measured major and trace element sample concentrations ( $\mathrm{Na}, \mathrm{Mg}, \mathrm{Ca}, \mathrm{Al}, \mathrm{Fe}, \mathrm{S}, \mathrm{K}, \mathrm{Ti}, \mathrm{Sr}, \mathrm{Cd}, \mathrm{Cs}, \mathrm{Ba}, \mathrm{Pb}, \mathrm{Bi}, \mathrm{U}, \mathrm{As}, \mathrm{V}$, $\mathrm{Cr}, \mathrm{Mn}, \mathrm{Co}, \mathrm{Cu}, \mathrm{Zn}, \mathrm{La}, \mathrm{Ce}, \mathrm{Pr}$ ) by inductively coupled plasma mass spectrometry (ICP-MS) using a Thermo Element2 at the Climate Change Institute, University of Maine, Orono, USA (Osterberg and others, 2006). The seasonal variations in stable water isotopes, sea-salt $\mathrm{Na}$ and dust (represented by many trace elements, including $\mathrm{Al}$, Fe, $\mathrm{Ti}, \mathrm{U}$ and rare earth elements) are well defined and can be used to annually date the cores (McConnell and others, 2000; Mosley-Thompson and others, 2001). We used multiple chemical time series to determine annual demarcations in each core record, and different analytes were favored for timescale development at each site, depending on local site characteristics. For example, stable water isotopes were strongly diffused at the low-accumulation Galen core site $\left(0.12 \mathrm{~m}\right.$ w.e. $\left.\mathrm{a}^{-1}\right)$, so spring dust peaks and winter sea-salt $\mathrm{Na}$ peaks were preferentially used to develop the timescale. In contrast, stable water isotopes and dust

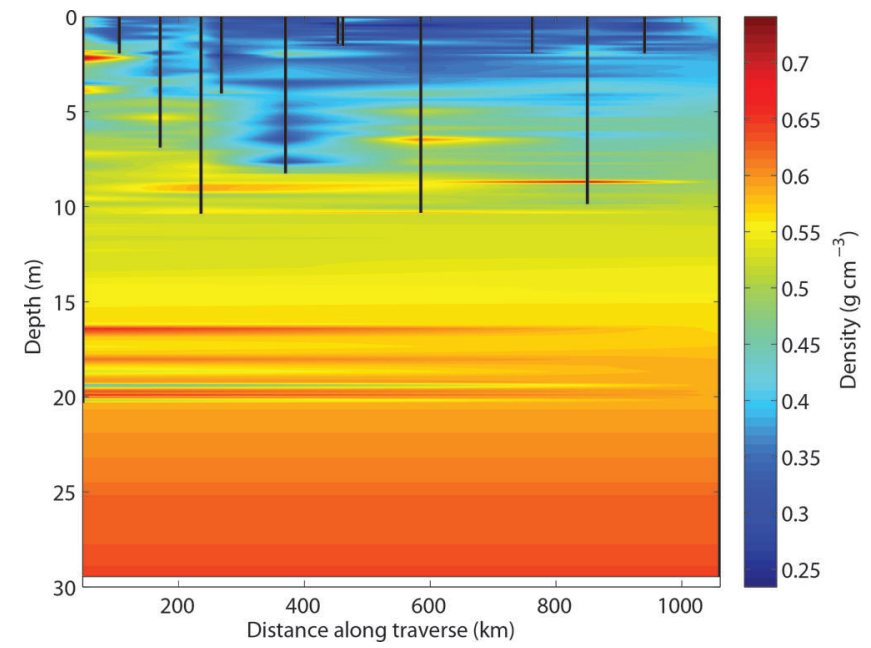

Fig. 3. Densities used for calculation of electromagnetic wave velocity in this study. Vertical black lines indicate the position and depth of measured density profiles. Densities are linearly interpolated between the nearest two profiles at any given depth. The left and right boundary data come from the '2Barrel' and Summit cores, respectively. Note that this procedure results in the lateral extension of density features that are, in reality, probably quite localized. This has an extremely small effect on the actual wave speed calculated for each profile. 
Table 1. Ages of the $12 \mathrm{IRH}$ s used in this study, derived from chemical stratigraphy at core locations. The match of layer ages at locations over $1000 \mathrm{~km}$ apart indicates clearly that the IRHs are isochronous

$\begin{array}{ccccc}\text { Layer Depth at } & \begin{array}{c}\text { Date at } \\ \text { 2Barrel } \\ \text { 2Barrel }\end{array} & \begin{array}{c}\text { Depth at } \\ \text { Galen }\end{array} & \begin{array}{c}\text { Date at } \\ \text { Galen }\end{array} \text { Depth at } & \text { Date at } \\ \text { Owen } & \text { Owen }\end{array}$

$\mathrm{m}$

$\begin{array}{rccccr}\text { 4.44 } & \text { Mar 2007 } & 1.91 & \text { Mar 2007 } & 2.73 & \text { Apr 2007 } \\ 6.37 & \text { Jun 2005 } & 2.64 & \text { Sept 2005 } & 3.76 & \text { Sept 2005 } \\ 8.68 & \text { Jun 2003 } & 3.28 & 2004 & 4.88 & 2004 \\ 11.13 & \text { Mar 2001 } & 4.01 & 2002 & 6.01 & 2002 \\ 12.51 & \text { Sept 1999 } & 4.69 & \text { Sept 1999 } & 7.03 & \text { Mar 2000 } \\ 14.76 & \text { Apr 1997 } & 5.61 & \text { Jan 1997 } & 8.16 & 1998 \\ 16.98 & \text { Apr 1995 } & 6.20 & \text { Feb 1995 } & 9.34 & \text { Sept 1995 } \\ 19.53 & \text { Aug 1991 } & 7.25 & \text { Jan 1991 } & 10.80 & \text { May 1992 } \\ 23.88 & - & 8.17 & \text { Sept 1988 } & 12.54 & \text { Apr 1988 } \\ 26.04 & - & 8.76 & \text { Aug 1986 } & 13.32 & \text { Jan 1986 } \\ 27.10 & - & 9.28 & \text { Jun 1984 } & 14.08 & \text { Jun 1983 } \\ 29.19 & - & 9.97 & - & 14.99 & \text { Mar 1980 }\end{array}$

were preferred for the 2Barrel depth/age scale, because meltwater percolation at the site more strongly eluted salts than dust particles (Wong and others, 2013). The uncertainty of the timescales is estimated to be \pm 0.5 years, based on repeated independent annual-layer counts.

\section{Identifying internal reflecting horizons}

In the radargram of Figure 2, many identifiable IRHs are visible. We manually selected clear, strong IRHs that could be consistently traced for the full length of the traverse route. For the purposes of our manual picking, we chose to follow local maxima in the radar return. Where a layer appeared to bifurcate (occasionally this happens when accumulation increases and existing layers become discernible within the ability of our radar), we continued the layers based on the dip and amplitude of surrounding layers (cf. Arcone and others, 2005). If this was not possible, or if the layer was discontinuous for more than several hundred meters alongtrack, we discarded the layer.

\section{Estimating uncertainty}

Uncertainty in our accumulation rates can arise from errors in correctly locating layers, errors in dating the layers and/or errors in the density used for converting to water equivalent. It is important to note that these error sources are independent of one another.

To assess error in layer picking, we note that our GPR settings result in a $\sim 0.03 \mathrm{~m}$ spacing between radar samples. Close inspection of the layers reveals that peaks defining IRHs are clear within \pm 2 samples, i.e. within $\pm 0.06 \mathrm{~m}$. With our average epoch length of 2.4 years, at a density of $0.5 \mathrm{~g} \mathrm{~cm}^{-3}$, this will introduce an error in accumulation of $0.0125 \mathrm{~m} \mathrm{a}^{-1}$.

The estimated uncertainty in dating is 0.5 year. At the lowest-accumulation core (Galen) the smallest distance between layers we used was $0.26 \mathrm{~m}$ w.e. over an epoch of 2.2 years. This gives an uncertainty in accumulation due to dating of $\sim \pm 0.02 \mathrm{~m} \mathrm{a}^{-1}$.

Karlöf and others (2005) estimated the error in measuring density using similar techniques as $1.4 \%$. If this is an optimistic estimate and our measurements resulted in twice as much error, the resulting $2.8 \%$, even

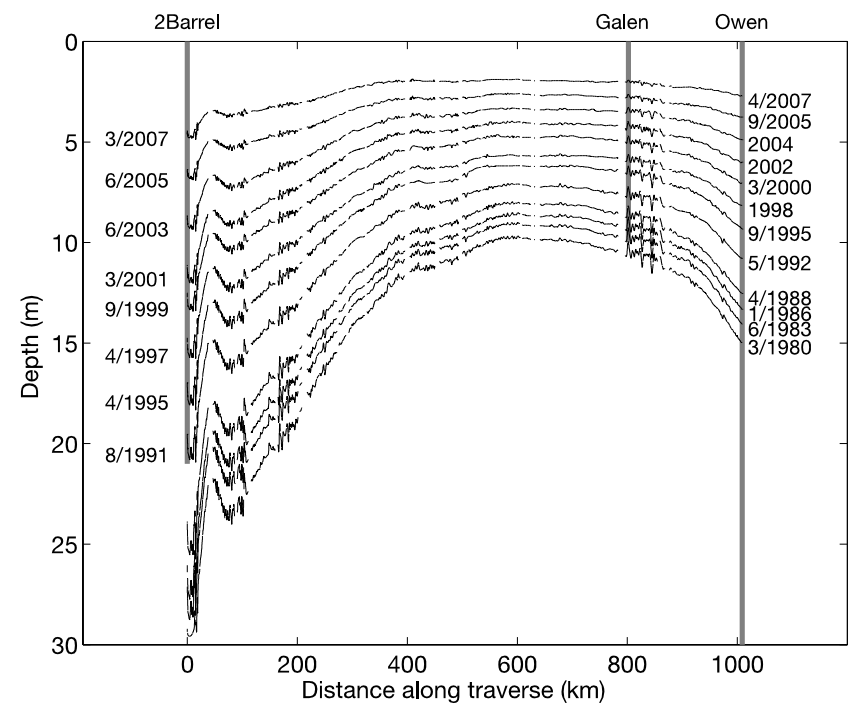

Fig. 4. Dated isochronous IRHs found in our radar data. Differences in the depth of a horizon along the traverse are driven by differences in accumulation. Cores from which dates were derived are shown in gray, with dates (m/yyyy) for the layers at each end of the traverse. Note the 'wavy' sections at $\sim 190$ and $\sim 820 \mathrm{~km}$, which are real small-scale variations in accumulation rate, driven by local topography (Black and Budd, 1964).

at higher-accumulation sites, results in errors in accumulation of $\sim \pm 0.014 \mathrm{~m} \mathrm{a}^{-1}$. As this scales with accumulation, error in accumulation measurement due to uncertainty in density is much lower over most of the traverse.

These errors are all random, not systematic, and thus are not additive. It is then most reasonable to average the errors together; thus we estimate an uncertainty in our accumulation rates due to all causes at $\sim 0.015 \mathrm{~m} \mathrm{a}^{-1}$. Because these errors are random and not systematic, they are unlikely to contribute to a bias.

\section{RESULTS}

The depth/age scales from the cores allow us to demonstrate the isochronous nature of the IRHs. The depth and age of the IRHs are summarized in Table 1; the IRHs we have delineated are clearly isochrones, as ages of the IRHs are nearly identical at all core sites. We take the date of any given traced IRH as the date of the Owen core from the depth at which the layer intersects the core. The final dated layers with depth and age can be seen in Figure 4.

To calculate an accumulation rate between two dated IRHs at each $20 \mathrm{~m}$ stacked GPR trace, we subtract the depth of one layer from the other to determine a firn thickness. We then convert the firn thickness to water equivalent by multiplying the thickness by the average density of the firn between the two IRHs. We then divide by the difference in the ages of the two IRHs to determine an average accumulation rate for the period between the two IRHs. Our accumulation rate estimates are presented in Figure 5.

Several spatial features are evident in these accumulation profiles. The broad trend in accumulation is higher values near the coast giving way to lower accumulation inland as the traverse route gains altitude; this trend is consistent with orographic lifting causing the most precipitation closer to the coast. Accumulation rates then rise again just before approaching Summit, as the traverse curves back south. 


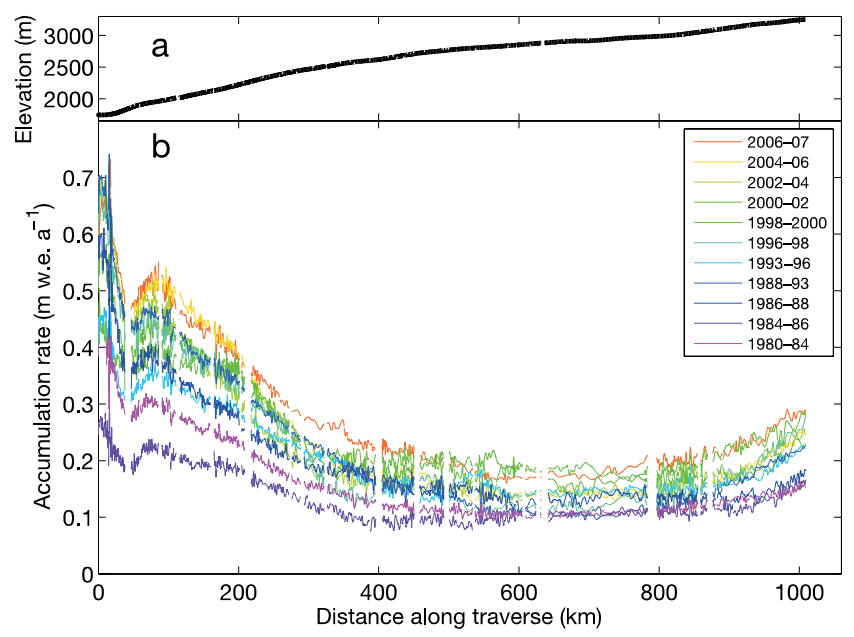

Fig. 5. (a) Elevation profile of the traverse route. (b) Accumulation rates by time period along the GrIT traverse, as determined from the depths of radar IRH isochrones. As is clear from the broad pattern of IRH depth, accumulation is greatest at the lower-elevation flanks nearer the coast, and smallest inland.

On a smaller scale, the effect of small-scale $(5-10 \mathrm{~km}$ wavelength) local topography is evident in the measured accumulation rates; as noted by Black and Budd (1964) in the Antarctic, local surface curvature can drive short-scale accumulation patterns, in which concave regions tend to receive greater accumulation and convex areas receive lower accumulation. This effect can be seen at $\sim 820 \mathrm{~km}$ in both Figures 4 and 6 , with the variability increasing with depth in Figure 4, as expected. Miège and others (2013) noted similar accumulation features in radar measurements collected in southeast Greenland.

\section{DISCUSSION}

\section{Comparison with modeled accumulation rates}

Burgess and others (2010) used firn cores and coastal precipitation records to calibrate the precipitation output of the Polar MM5 numerical regional climate model, producing annual modeled accumulation grids for Greenland for the years 1958-2008, accessible for download at http:// bprc.osu.edu/Greenland_accumulation/. We use nearestneighbor interpolation along the traverse to determine a MM5 modeled accumulation rate for each $20 \mathrm{~m}$ GPR trace for which we have measured accumulation, and summarize the comparison in Figure 6.

On average, differences are small (median $-0.012 \mathrm{~m}$; mean $0.001 \mathrm{~m}$ ). However, biases are highly correlated into two regions. In the lower-accumulation interior of the ice sheet ( 250-1000 km), at higher elevations, MM5 typically overestimates accumulation rates slightly (by $0.014 \mathrm{~m}$ ), while in the higher-accumulation, lower-elevation marginal area near the coast, MM5 typically underestimates average accumulation by 0.0386-0.0466 m w.e. (median and mean, respectively). As is evident in the measured accumulation rates, this is a region of high spatial variability. The spatial accumulation maps of Burgess and others (2010) show a high-accumulation region in this area, probably related to a combination of factors: southerly flow from Baffin Bay during storms combined with orographic lifting combines with the close proximity to the North Water Polynya (the

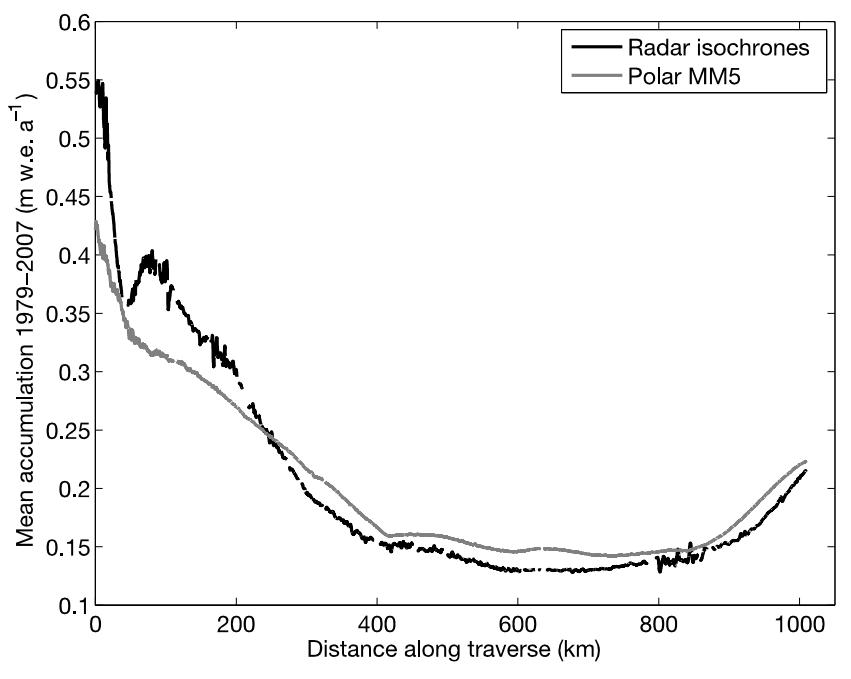

Fig. 6. Average accumulation from 1979 to 2007 determined using radar isochrones (black curve) and estimated from the Polar MM5 calculations (gray curve; Burgess and others, 2010). Clearly Polar MM5 captures the broad spatial trend along most of the traverse. The relatively large differences from 0 to $200 \mathrm{~km}$ can be partially attributed to the spatial pattern of accumulation near the coast; the GrIT route transects a region there of large spatial variability. Note that the MM5 model output does not capture the small-scale variability associated with small-scale changes in topography (e.g. at $\sim 820 \mathrm{~km})$.

largest polynya in the world, $8.5 \times 10^{4} \mathrm{~km}^{2}$ ), increasing moisture content of these storms in winter. As this northern end of the traverse route runs almost parallel to the accumulation contours, subtle variations in the route cause large changes in measured accumulation.

It is worth noting that the region that MM5 underestimates by up to $25 \%$, within $200 \mathrm{~km}$ of the coast, is the region that shows the most change since 1955 (Fig. 9, below), and also the area with the highest accumulation. Thus, accumulation estimates from MM5 do not capture the increase we see since the 1950s. It is possible that this is a resolution issue in a region of high accumulation gradient, or it may be that MM5 does not capture the other possible climate changes contributing to the increase. The Wilcoxon signed-rank test finds these differences to be significant $\left(p=2.2 \times 10^{-16}\right)$. This test was chosen over a $t$-test because the Shapiro-Wilk normality test showed both datasets to be non-normally distributed ( $p$-value MM5 $=2.2 \times 10^{-16}$; $p$-value GPR $\left.=2.2 \times 10^{-16}\right)$, as are their differences $\left(p\right.$-value $\left.{ }_{\mathrm{GPR}-\mathrm{MM} 5}=2.2 \times 10^{-16}\right)$.

At a shorter length scale $(\sim 10 \mathrm{~km})$, the measured accumulation rates show subtle spatial changes related to surface topography, as noted above. Figure 7 illustrates the relationship between accumulation and small-scale topography along a $30 \mathrm{~km}$ segment of the traverse close to Summit. The highs in accumulation (e.g. $845 \mathrm{~km}$ in Fig. 7) correspond to local dips in topography, creating concave areas that accumulate more snow. The modeled accumulation rate does not show these small-scale effects, as its $24 \mathrm{~km}$ gridscale is independent of small-scale surface topography.

To illustrate temporal changes in accumulation over our measurement period, we plot time series of accumulation near each end of the traverse in Figure 8. At the northern, higher-accumulation, lower-elevation end of the traverse, 


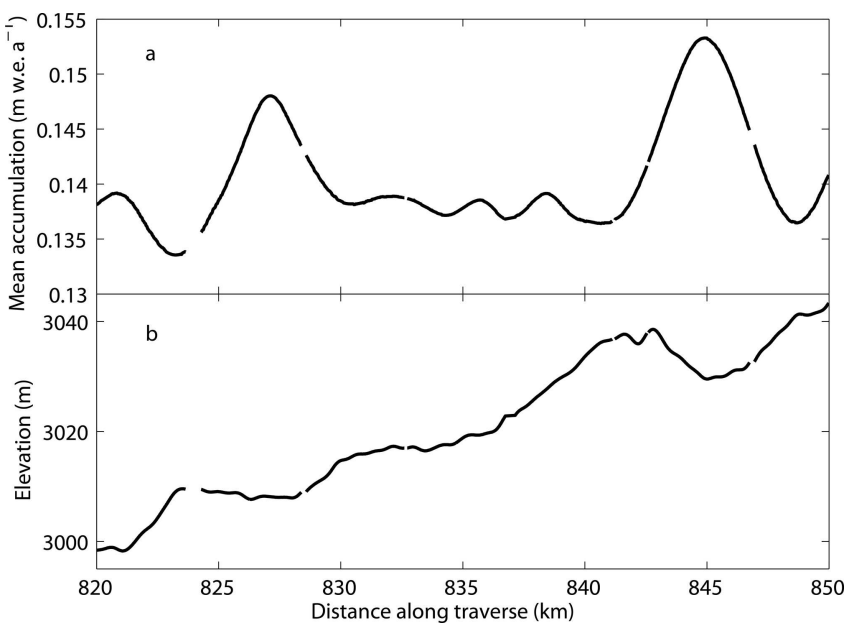

Fig. 7. Detail of a $30 \mathrm{~km}$ section of the traverse, showing the effect of local topography on accumulation. (a) Mean accumulation as determined from radar IRHs, over the period 1979-2007. (b) Surface elevation along the same $30 \mathrm{~km}$ traverse section. As reported by others (Black and Budd, 1964; Hawley and others, 2006; Miège and others, 2013), the highs in accumulation correspond with local dips in topography, creating convex areas that accumulate more snow.

though there is an offset in average accumulation rate (as seen in Fig. 6), the changes in accumulation rate correlate closely $\left(r^{2}=0.5158, p=0.0128\right)$, indicating that the calibrated MM5 model captures the interannual trends in accumulation well. At the southern, lower-accumulation, higher-elevation end of the traverse, the interannual changes are more subtle, and the correlation between measured and modeled series is lower and not statistically significant $\left(r^{2}=0.2610, p=0.1083\right)$.

\section{Comparison with 1950s in situ measurements}

Benson (1962) measured accumulation rates in a series of snow pits along a similar route to ours in 1952-55 (Fig. 1).

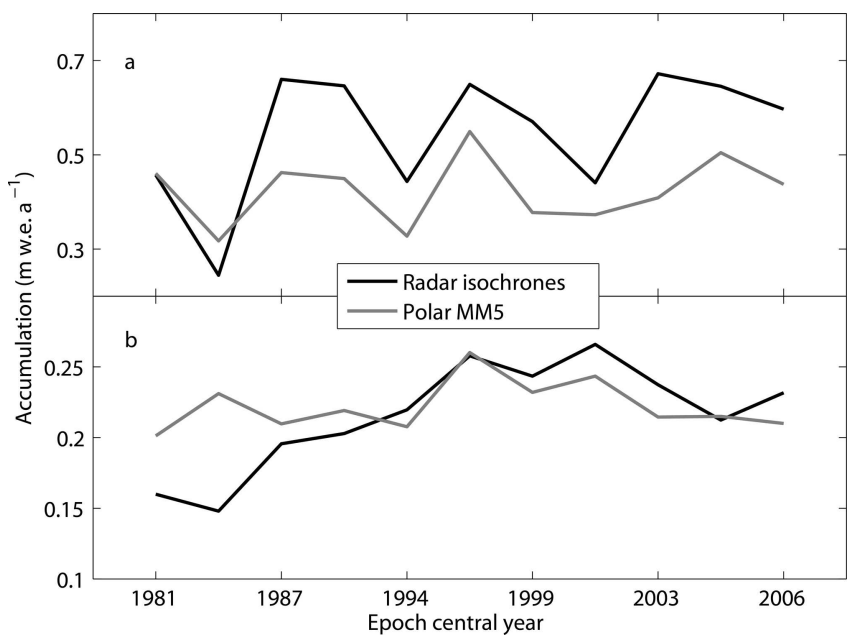

Fig. 8. Temporal trends seen in both Polar MM5 and accumulations from radar isochrones. The central year of each measurement epoch is on the $x$-axis. (a) Accumulations at the 2Barrel site; here changes in accumulation rate correlate closely $\left(r^{2}=0.5158, p=0.0128\right)$, indicating that the calibrated MM5 model captures the interannual trends in accumulation well. (b) Accumulations at Summit; here the correlation between measured and modeled series is lower, and not statistically significant $\left(r^{2}=0.2610, p=0.1083\right)$.

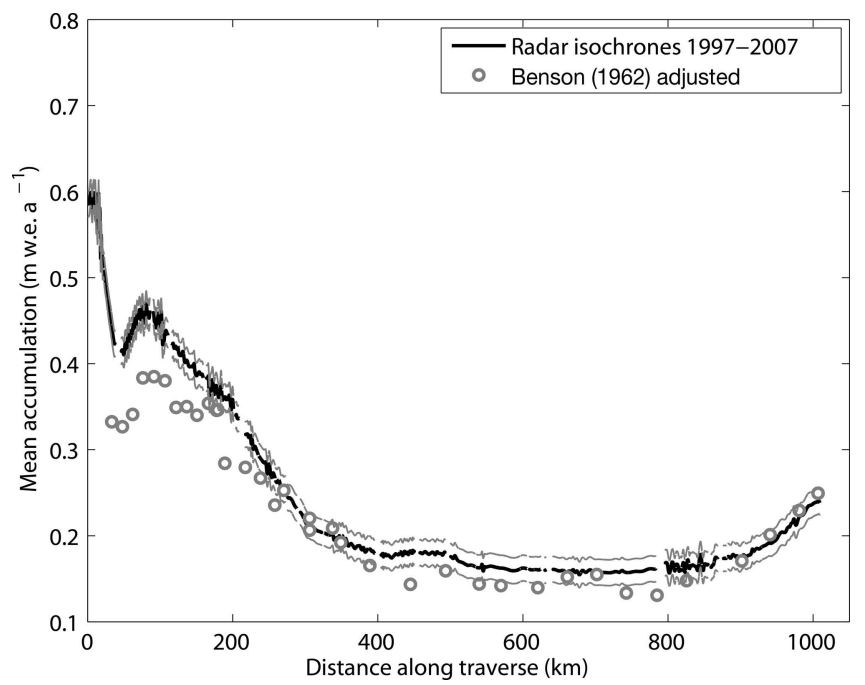

Fig. 9. Mean accumulation over the period 1997-2007 measured using radar isochrones (black curve), with potential uncertainty (gray curves) and mean accumulation over the period 1945-55 measured in snow pits by Benson (1962) (gray circles). Because the pits and radar transect are not spatially coincident, the Benson (1962) accumulations have been adjusted using the 1958 spatial pattern of accumulation modeled by Burgess and others (2010). The Benson (1962) accumulations are on average $0.022 \mathrm{mw} . e . \mathrm{a}^{-1}$ lower, indicating a $\sim 2 \%$ decade $^{-1}$ change in accumulation rates over the past five decades.

Our modern measurements thus allow us to investigate changes in accumulation rates over the 52 years between traverses. The different routes taken by the two traverses (Fig. 1) require that we disentangle spatial changes in accumulation from temporal changes. In order to compare the two datasets, we corrected the accumulation rates of Benson (1962) using the spatial pattern of accumulation for 1958 (Fig. 1), the earliest year of MM5 output presented by Burgess and others (2010). For each accumulation location presented by Benson (1962), we calculated the closest point along the GrIT. We then interpolated the 1958 Polar MM5 accumulation rates between the two points (Benson's and GrIT's) to find a spatial correction value to be added to the Benson (1962) data for comparison. It is possible that one or more of Benson's snow pits were located in areas of topographical roughness, which can affect accumulation rates (Fig. 7), and it is important to note that we cannot account for this effect.

The adjusted accumulations of Benson (1962) are shown in Figure 9, together with our 10 year average accumulation rate and $1 \sigma$ range from 1997-2007. A subtle but persistent positive difference is evident along the traverse (Fig. 9). On average the GPR-derived modern rate was 0.022-0.031 mw.e. $\mathrm{a}^{-1}$ greater than the Benson values, based on the mean and median differences, respectively. The one-sided non-parametric Wilcoxon signed-rank test shows that the positive difference between paired observations along the traverse is statistically significant $(p=0.0000076)$. This test was chosen over a $t$-test because both datasets were non-normally distributed, based on the Shapiro-Wilk normality test $(p$-value Benson $=0.001455$; $p$-value GPR $=0.000223)$, as were their differences ( $p$-value GPR-Benson $=0.0179)$. It is important to consider the possibility of differing measurement techniques contributing to this result. Benson (1962) used $500 \mathrm{~cm}^{3}$ SIPRE 
tubes to measure density and reports his overall accuracy to be $\pm 0.005 \mathrm{~g} \mathrm{~cm}^{3}$ or $\sim 1.5 \%$ at the densities he encountered. Thus it is unlikely that technique contributes to the difference in measured accumulation rates.

At the lower-elevation, coastal end of the traverse, the difference between Benson (1962) and GrIT accumulation values is more pronounced. This could be the result of decreasing sea-ice extent in Baffin Bay (Rayner and others, 2003), which would increase the moisture available to storms in this region, and potentially increase the strength of these storms.

The $0.022 \mathrm{~m}$ w.e. $\mathrm{a}^{-1}$ increase we find implies a $\sim 10 \%$ change in average accumulation in the dry-snow zone of the ice sheet in the past 52 years. The significance of this result is that increased accumulation, as seen on the East Antarctic ice sheet by Davis and others (2005), driven by the increased ability of warmer air to hold moisture, is also evident inland on the Greenland ice sheet. Box and others (2013) found a $\sim 1.2 \%$ decade $^{-1}$ increase over the 20th century, and our result is consistent with this, if slightly higher. The significance of this for the mass balance of the Greenland ice sheet, is that at least some of the increased mass loss from melting at the lower-elevation margins of the ice sheet is balanced by the small increases in mass gain from increased accumulation in the higher-elevation interior.

\section{CONCLUSIONS}

We have traced internal reflecting horizons in $400 \mathrm{MHz}$ radar data along $\sim 1000 \mathrm{~km}$ of the GrIT. Using densities measured along the traverse, we determined the depth of these reflecting horizons. We have shown these horizons to be isochrones using depth/age scales at each end of the traverse, with the ages of the layers at each end agreeing within an average of 2.5 months.

Using the isochrones and density measurements, we determined accumulation rates along the traverse for the period 1980-2007. These accumulation rates differ slightly from those modeled by Burgess and others (2010), both spatially and temporally over the coincident period. Though the modeled accumulations accurately reflect the largescale patterns in accumulation, they understandably fail to capture small-spatial-scale (tens of kilometers) accumulation anomalies $(\sim 10 \%)$ driven by surface topography.

Comparison of our measured accumulation rates with those measured in the 1950s by Benson (1962) indicates a $\sim 2 \%$ decade $^{-1}$ increase in accumulation between the periods 1945-55 and 1997-2007. Thus, due to a warmer atmosphere driving an increased capacity for moisture, and in common with the findings of Davis and others (2005) in East Antarctica, accumulation in the interior of the Greenland ice sheet has increased slightly in the currently warming climate.

\section{ACKNOWLEDGEMENTS}

This project was supported by the US National Science Foundation under grant NSF-OPP 0909265. The Owen core was drilled by Terry Gacke of the Ice Drilling and Design Office (IDDO), University of Wisconsin-Madison, USA. Logistical support was provided by Ch2M HILL Polar Services. Mike Handley was instrumental in processing our samples at the University of Maine. This work would not have been possible without the support of the traverse 'swing' crew, for which we are grateful. The authors thank and commend Burgess and others (2010) for making their results freely available. We also thank Clément Miège and an anonymous reviewer whose comments improved the manuscript. Finally, we thank Scientific Editor John Woodward and Chief Editor Jo Jacka for their handling of the manuscript.

\section{REFERENCES}

Alley RB, Spencer MK and Anandakrishnan S (2007) Ice-sheet mass balance: assessment, attribution and prognosis. Ann. Glaciol., 46, 1-7 (doi: 10.3189/172756407782871738)

Arcone SA, Spikes VB and Hamilton GS (2005) Stratigraphic variation in polar firn caused by differential accumulation and ice flow: interpretation of a $400 \mathrm{MHz}$ short-pulse radar profile from West Antarctica. J. Glaciol., 51(174), 407-422 (doi: 10.3189/172756505781829151)

Bales RC and 8 others (2009) Annual accumulation for Greenland updated using ice core data developed during 2000-2006 and analysis of daily coastal meteorological data. J. Geophys. Res., 114(D6), D06301 (doi: 10.1029/2008JD010600)

Benson CS (1962) Stratigraphic studies in the snow and firn of the Greenland ice sheet. SIPRE Res. Rep. 70, 76-83

Black HP and Budd W (1964) Accumulation in the region of Wilkes, Wilkes Land, Antarctica. J. Glaciol., 5(37), 3-15

Box JE, Bromwich DH and Bai L-S (2004) Greenland ice sheet surface mass balance for 1991-2000: application of Polar MM5 mesoscale model and in-situ data. J. Geophys. Res., 109(D16), D16105 (doi: 10.1029/2003JD004451)

Box JE and 10 others (2013) Greenland ice sheet mass balance reconstruction. Part I: net snow accumulation (16002009). J. Climate, 26(11), 3919-3934 (doi: 10.1175/JCLI-D-12$00373.1)$

Burgess EW and 6 others (2010) A spatially calibrated model of annual accumulation rate on the Greenland Ice Sheet (1958-2007). J. Geophys. Res., 115(F2), F02004 (doi: 10.1029/ 2009JF001293)

Davis CH, Li Y, McConnell JR, Frey MM and Hanna E (2005) Snowfall-driven growth in East Antarctic ice sheet mitigates recent sea-level rise. Science, 308(5730), 1898-1901 (doi: 10.1126/science.1110662)

Dibb JE and Fahnestock M (2004) Snow accumulation, surface height change, and firn densification at Summit, Greenland: insights from 2 years of in situ observation. J. Geophys. Res., 109(D24), D24113 (doi: 10.1029/2003JD004300)

Drinkwater MR, Long DG and Bingham AW (2001) Greenland snow accumulation estimates from satellite radar scatterometer data. J. Geophys. Res., 106(D24), 33 935-33 950 (doi: 10.1029/ 2001JD900107)

Hanna E and 12 others (2011) Greenland Ice Sheet surface mass balance 1870 to 2010 based on Twentieth Century Reanalysis, and links with global climate forcing. J. Geophys. Res., 116(D24), D24121 (doi: 10.1029/2011JD016387)

Hawley RL, Morris EM, Cullen R, Nixdorf U, Shepherd AP and Wingham DJ (2006) ASIRAS airborne radar resolves internal annual layers in the dry-snow zone of Greenland. Geophys. Res. Lett., 33(4), L04502 (doi: 10.1029/2005GL025147)

Hawley RL, Morris EM and McConnell JR (2008) Rapid techniques for determining annual accumulation applied at Summit, Greenland. J. Glaciol., 54(188), 839-845 (doi: 10.3189/ 002214308787779951)

Kanagaratnam P, Gogineni SP, Gundestrup N and Larsen L (2001) High-resolution radar mapping of internal layers at the North Greenland Ice Core Project. J. Geophys. Res., 106(D24), 33 799-33 811 (doi: 10.1029/2001JD900191)

Karlöf L and 11 others (2005) Accumulation variability over a small area in east Dronning Maud Land, Antarctica, as determined from shallow firn cores and snow pits: some implications for 
ice-core records. J. Glaciol., 51(174), 343-352 (doi: 10.3189/ 172756505781829232)

King RW and Bock Y (2009) Documentation for the GAMIT GPS Analysis Software, release 10.35. Massachusetts Institute of Technology, Cambridge, MA

Kovacs A, Gow AJ and Morey RM (1995) The in-situ dielectric constant of polar firn revisited. Cold Reg. Sci. Technol., 23(3), 245-256 (doi: 10.1016/0165-232X(94)00016-Q)

Lemke P and 10 others (2007) Observations: changes in snow, ice and frozen ground. In Solomon S and 7 others eds. Climate change 2007: the physical science basis. Contribution of Working Group I to the Fourth Assessment Report of the Intergovernmental Panel on Climate Change. Cambridge University Press, Cambridge, 339-383

McConnell JR and 7 others (2000) GAMIT 10.35 analysis software. Nature, 406(6798), 877-879 (doi: 10.1038/35022555)

Miège $C$ and 6 others (2013) Southeast Greenland high accumulation rates derived from firn cores and ground-penetrating radar. Ann. Glaciol., 54(63 Pt 2), 322-332 (doi: 10.3189/ 2013AoG63A358)

Mosley-Thompson E and 8 others (2001) Local to regional-scale variability of annual net accumulation on the Greenland ice sheet from PARCA cores. J. Geophys. Res., 106(D24), 33 839-33 851 (doi: 10.1029/2001JD900067)

Ohmura A and Reeh N (1991) New precipitation and accumulation maps for Greenland. J. Glaciol., 37(125), 140-148
Osterberg EC, Handley MJ, Sneed SB, Mayewski PA and Kreutz KJ (2006) Continuous ice core melter system with discrete sampling for major ion, trace element, and stable isotope analyses. Environ. Sci. Technol., 40(10), 3355-3361 (doi: 10.1021/es052536w)

Rayner NA and 7 others (2003) Global analyses of sea surface temperature, sea ice, and night marine air temperature since the late nineteenth century. J. Geophys. Res., 108(D14), 4407 (doi: 10.1029/2002JD002670)

Rignot E, Box JE, Burgess E and Hanna E (2008) Mass balance of the Greenland ice sheet from 1958 to 2007. Geophys. Res. Lett., 35(20), L20502 (doi: 10.1029/2008GL035417)

Spikes VB, Hamilton GS, Arcone SA, Kaspari S and Mayewski P (2004) Variability in accumulation rates from GPR profiling on the West Antarctic plateau. Ann. Glaciol., 39, 238-244 (doi: 10.3189/172756404781814393)

Wong GJ, Hawley RL, Lutz ER and Osterberg EC (2013) Traceelement and physical response to melt percolation in Summit (Greenland) snow. Ann. Glaciol., 54(63 Pt 1), 52-62 (doi: 10.3189/2013AoG63A602)

Wouters B, Chambers D and Schrama EJO (2008) GRACE observes small-scale mass loss in Greenland. Geophys. Res. Lett., 35(2), L20501 (doi: 10.1029/2008GL034816)

Zwally HJ and 11 others (2011) Greenland ice sheet mass balance: distribution of increased mass loss with climate warming; 2003-07 versus 1992-2002. J. Glaciol., 57(201), 88-102 (doi: $10.3189 / 002214311795306682)$

MS received 13 July 2013 and accepted in revised form 29 November 2013 